\title{
MicroRNAs Are Involved in Regulating Plant Development and Stress Response through Fine-Tuning of TIR1/AFB-Dependent Auxin Signaling
}

\author{
Pan Luo ${ }^{1, *,+}$, Dongwei Di ${ }^{2, *,+}\left(\mathbb{D}\right.$, Lei Wu ${ }^{3} \mathbb{D}$, Jiangwei Yang ${ }^{1}$, Yufang Lu ${ }^{2}$ and Weiming Shi ${ }^{2}$ \\ 1 College of Life Science and Technology, Gansu Agricultural University, Lanzhou 730070, China; \\ yjw@gsau.edu.cn \\ 2 State Key Laboratory of Soil and Sustainable Agriculture, Institute of Soil Science, Chinese Academy of \\ Sciences, Nanjing 210008, China; yflu@issas.ac.cn (Y.L.); wmshi@issas.ac.cn (W.S.) \\ 3 MOE Key Laboratory of Cell Activities and Stress Adaptations, School of Life Sciences, Lanzhou University, \\ Lanzhou 730000, China; leiwu@lzu.edu.cn \\ * Correspondence: luopan@gsau.edu.cn (P.L.); dwdi@issas.ac.cn (D.D.) \\ + These authors contribute equally to this work.
}

check for updates

Citation: Luo, P.; Di, D.; Wu, L. Yang, J.; Lu, Y.; Shi, W. MicroRNAs Are Involved in Regulating Plant Development and Stress Response through Fine-Tuning of TIR1/AFB-Dependent Auxin Signaling. Int. J. Mol. Sci. 2022, 23, 510. https://doi.org/10.3390/ ijms23010510

Academic Editors: Georgy A. Romanov and Karen Skriver

Received: 11 November 2021 Accepted: 1 January 2022

Published: 3 January 2022

Publisher's Note: MDPI stays neutral with regard to jurisdictional claims in published maps and institutional affiliations.

Copyright: (C) 2022 by the authors. Licensee MDPI, Basel, Switzerland. This article is an open access article distributed under the terms and conditions of the Creative Commons Attribution (CC BY) license (https:// creativecommons.org/licenses/by/ $4.0 /)$.

\begin{abstract}
Auxin, primarily indole-3-acetic acid (IAA), is a versatile signal molecule that regulates many aspects of plant growth, development, and stress response. Recently, microRNAs (miRNAs), a type of short non-coding RNA, have emerged as master regulators of the auxin response pathways by affecting auxin homeostasis and perception in plants. The combination of these miRNAs and the autoregulation of the auxin signaling pathways, as well as the interaction with other hormones, creates a regulatory network that controls the level of auxin perception and signal transduction to maintain signaling homeostasis. In this review, we will detail the miRNAs involved in auxin signaling to illustrate its in planta complex regulation.
\end{abstract}

Keywords: auxin signal; TIR1/AFBs (Transport Inhibitor Response 1/ Auxin Signaling F-Box Protein); microRNA; precise regulation

\section{Introduction}

The plant growth regulator, auxin, participates in nearly all aspects of plant growth and development, including cell expansion, vascular differentiation, lateral root (LR) formation, hypocotyl elongation, senescence, abscission, hormone crosstalk and stress responses [1-4]. The most common natural auxin is indole-3-acetic acid (IAA), which can perform most of the regulatory functions of auxins in plants [5]. In addition, indole-3-butyric acid (IBA), 4-chloroindole-3-acetic acid (4-Cl-IAA), and phenylacetic acid (PAA) have been also detected in plants [6,7]. One of the most fascinating questions in auxin biology is how such a simple signal molecule can exhibit distinct functions in plants [8].

Auxin is mainly perceived by a co-receptor complex that consists of two protein families, the Transport Inhibitor Response 1/Auxin Signaling F-box Protein (TIR1/AFB) family and the Auxin/Indole Acetic Acid (Aux/IAA) family. After auxin perception by the $\mathrm{SCF}^{\mathrm{TIR} 1 / \mathrm{AFB}}$-Aux/IAA complex, the transcription of downstream genes is regulated directly by a third protein family, the Auxin Response Factor (ARF) family [8]. Auxin acts as an adaptor that determines which protein will be bound with an Aux/IAA transcriptional repressor. In the absence of auxin, the Aux/IAAs bind to the ARF transcriptional factors to inhibit ARF mediated auxin-responsive genes transcription; however, when auxin is present, it mediates the binding of Aux/IAA proteins to $\mathrm{SCF}^{\mathrm{TIR} 1 / \mathrm{AFB}}$ to form a SCF ${ }^{\mathrm{TIR} 1 / \mathrm{AFB}}$. Aux/IAA complex, which leads to the ubiquitination and degradation of Aux/IAA by the $26 \mathrm{~S}$ proteasome and frees the ARFs to regulate up or down their target genes [9]. 
Interestingly, auxin cannot bind the TIR1 directly without an Aux/IAA [9]. Many auxinresponsive genes fall into one of three major families: SAUR (Small auxin up RNA), Aux/IAA, and GH3 (Gretchen Hagen 3) [10,11].

In addition to the precise regulation of auxin biosynthesis and distribution, the auxin signaling pathway is subject to locus-specific control by microRNAs (miRNA) [12,13]. The miRNAs are short, single-stranded nucleic acid molecules ( 21-24 nucleotides) that repress target gene expression as an additional layer of regulation of plant growth, and stress responses in plants [14]. In plants, primary miRNAs (pri-miRNAs) are endogenously expressed from miRNA-encoding genes (MIRs) by the DNA-dependent RNA polymerase II (Pol II) [15]. The pri-miRNA is cleaved by RNase III enzymes Dicer-Like 1(DCL1)/DCL4 and then processed into a mature miRNA by a protein complex composed of Serrate (SE), Hyponastic Leaves 1 (HY1), Touch and DCL1 [16]. The miRNA biogenesis is also regulated by various protein factors at the transcriptional and posttranscriptional levels [17]. A recent study reports a new protein factor, SE-Associated Protein 1 (SEAP1), that associates with the DCL1 complex and promotes the interaction of the DCL1 complexes with pri-miRNAs, facilitating pri-miRNA splicing, processing, and/or stability [17]. The miRNAs regulate gene expression by directly cleaving target mRNA or inhibiting translation in the cytoplasm through conserved Argonaute (AGO) proteins [16]. In addition, miRNAs can bind to target promoters in the nucleus, thereby regulating expression [18], suggesting that miRNAs can function as a gene activator or repressor. In plants, miRNAs exhibit high evolutionarily conserved complementarity to mRNAs among dicot and monocot species [19]. Conserved miRNAs may play important roles in basic development and signal transduction, while nonconserved miRNAs may play particular roles in different tissues or plant species under special environmental conditions [20-22].

The genes involved in auxin signal transduction are the targets of multiple miRNAs, with some genes extensively studied in relation to plant growth and stress responses. The miRNA-mediated regulation of auxin signaling is generally divided into two types: (i) by direct targeting of the genes involved in the auxin signaling pathway, including TIR1/AFBs, ARF and AUX/IAA; or (ii) by modulating free auxin content via indirect regulation of auxin biosynthesis, metabolism and transport. Here, we will mainly review the latest studies on miRNA-mediated regulation of the auxin pathway in the dicot Arabidopsis (Arabidopsis thaliana) and the monocot rice (Oryza sativa), as well as some new findings in other species, in order to provide a comprehensive picture of the role of miRNAs in auxin signaling and how they finely regulate development and stress responses in the plant kingdom.

\section{2. miRNA-Mediated Regulation of Auxin Signaling and Homeostasis}

2.1. Two Conserved miRNAs, miR160 and miR167, Constitute a Complex Feedback Loop to Regulate Auxin Signaling and Homeostasis

The miRNAs, miR160 and miR167, are two conserved regulators of the auxin signaling pathway. They modulate the expression of several AUXIN RESPONSE FACTOR (ARF) genes, which function as activators or repressors of primary auxin responsive genes in plants [23-25]. In Arabidopsis, miR160 directly cleaves the mRNA of AtARF10/16/17, while miR167 cleaves AtARF6/8 [26-30]. Plants expressing miRNA-resistant forms of these $A R F s$ exhibit pleiotropic developmental defects, indicating the essential roles of miR160 and miR167 in Arabidopsis growth and development $[27,28]$. Surprisingly, there are multiple feedback points in the miR160-miR167/ARF regulatory network.

miR160/167 and AtARF6/8/17 constitute a regulatory network that controls adventitious rooting [26]. In this regulatory network, miR160/ARF17 is a negative regulator of adventitious rooting, while $\mathrm{miR} 167 / \mathrm{ARF} 6 / 8$ is a positive regulator. These three ARFs precisely control their own expression at both the transcriptional and posttranscriptional levels by regulating miR160 and miR167 availability, while miR160 and miR167 homeostasis also provides feedback control by AtARF6/8/17 [26] (Figure 1A). Moreover, the expression of miRNA-resistant AtARF17 in transgenic Arabidopsis plants (mAtARF17) 
increases the level of $A t A R F 17$, which alters the accumulation of the auxin-conjugating genes $A t G H 3.2 / 3.3 / 3.5 / 3.6$ and results in pleiotropic developmental defects [28], suggesting that the miR160/ARF17 module is more critical for proper development via regulation of IAA homeostasis.
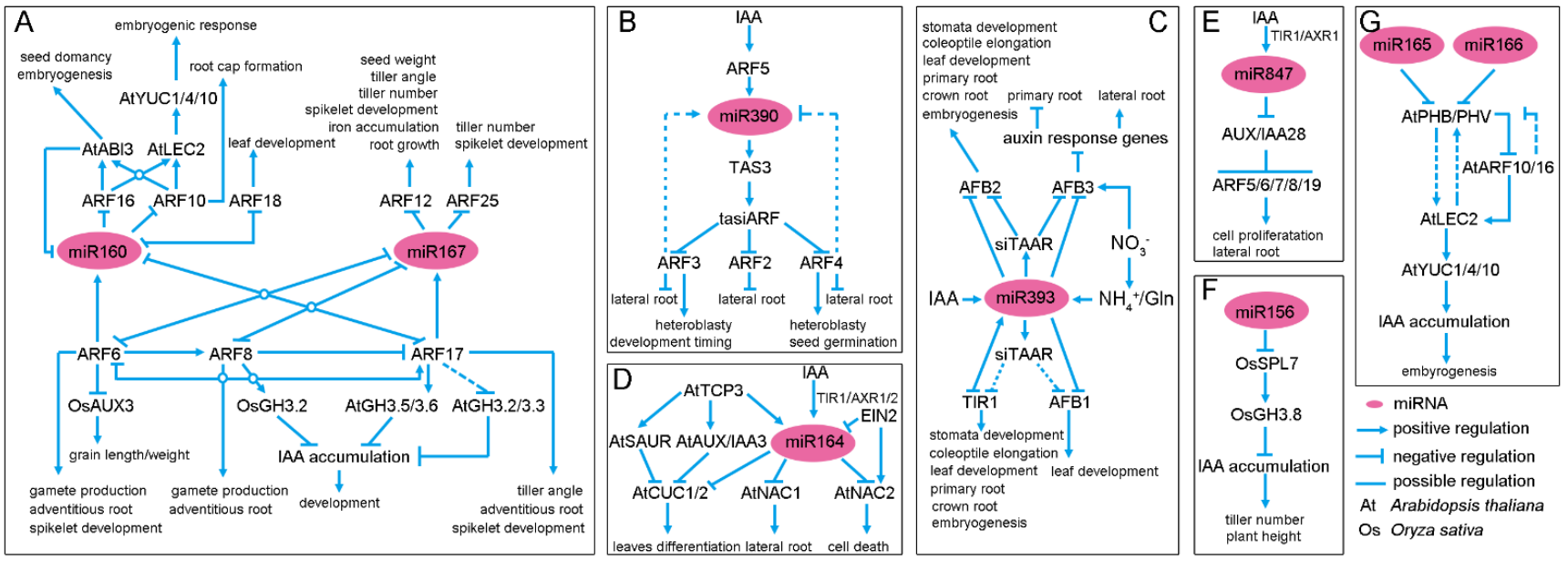

Figure 1. Overview of miRNA-mediated regulatory modules of plant growth and development in Arabidopsis and rice. (A-G) summary of the molecular connections between specific miRNAs and components of the auxin signaling pathway: (A) miR160 and miR167; (B) miR390; (C) miR393; (D) miR164; (E) miR847; (F) miR156, and (G) miR165 and miR166. Abbreviation: TIR1, Transport Inhibitor Response 1; AFB, Auxin F-box Protein; ARF, Auxin Response Factor; LEC2, Leafy Cotyledon 2; AUX/IAA, Auxin/Indole Acetic Acid; ABI3, ABA Insensitive 3; AUX3, Auxin Resistant 3; GH3, Gretchen Hagen 3; TAS3, Trans-Acting SiRNA 3; tasiARF, trans-acting small interfering ARF; TCP3, Teosinte branched/Cycloidea/PCF Transcription Factor 3; SAUR, Small Auxin-Up RNA; CUC, Cup-Shaped Cotyledon; NAC, NAC Domain-Containing protein; EIN2, Ethylene Insensitive 2; AXR1/2, Auxin Resistant 1/2; $\mathrm{NH}_{4}{ }^{+}$, ammonium; $\mathrm{NO}_{3}{ }^{-}$, nitrite; Gln, glutamine; siTAAR, small interfering RNA of AFB2/3; SPL7, Squamosal Promoter binding protein-Like 7; PHB/PHV, PHABULOSA/PHAVOLUTA; YUC, Flavin-binding monooxygenase family protein.

In addition to the control of root growth, the miR160/ARF10/16/ABSCISIC ACID INSENSITIVE 3 (ABI3) regulatory loop is also essential for several opposite processes, including seed dormancy, seed germination, and somatic embryogenesis [27,31-33]. Firstly, auxin can enhance ABA-mediated seed dormancy by employing AtARF10/16, the target genes of miR160, to maintain the transcription of AtABI3 [32]. Secondly, AtABI3 inhibits the transcription of miRNA-encoding gene AtMIR160b and then the decreased miR160 accumulation. As a result, the decreased miR160 post-transcriptionally regulates AtARF10/16, while AtARF10/16 may regulate the auxin level through AtLEC2-mediated AtYUC1/4/10 activation, which finally controls somatic embryogenesis [31-34]. Thirdly, the miR160/ARF10 module is also involved in regulating seed germination under different concentrations of ABA [27] (Figure 1A). Together, these results clearly suggest that the auxin and ABA signaling pathways synergically control seed dormancy and germination via the miR160/ARF10/16/ABI3 regulatory loop. Moreover, miR167 controls both male and female reproduction via regulating the expression patterns of AtARF6 and AtARF8 [30]. However, the environmental or developmental signals and the mechanisms underlying the transition of seed dormancy/germination and somatic embryogenesis still need to be further investigated.

Furthermore, miR160 and miR167 also respond to biotic or abiotic stresses (Figure 2A). The miR160 prompts the expression of heat shock proteins and plant development via reducing its targets, AtARF10/16/17, to allow plants to survive heat stress [35]. The miR167 is involved in the response to high osmotic stress by decreasing Indoleacetic Acid AlanineResistant3 (AtIAR3), a hydrolytic enzyme that generates an active form of auxin, but not 
AtARF6/8 [36]. In contrast, AtARF6/8 promotes jasmonic acid (JA) production [37], while JA induces the transcription of AtIAR3 (also named as JASMONATE RESPONSIVE3, JR3). The active IAA that is released by AtIAR3 also stimulates the expression of AtARF6/8. Thus, AtARF6/8 may be indirectly involved in the response to osmotic stress [36]. The miR167 also modulates the defense against pathogens through $A t A R F 6 / F 8$. Upon infection by the bacterial pathogen Pseudomonas syringae, overexpression of miR167 decreases AtARF6/8 levels and the size of stomatal apertures, which can reduce pathogen entry into leaves in cooperation with salicylic acid (SA) [38].
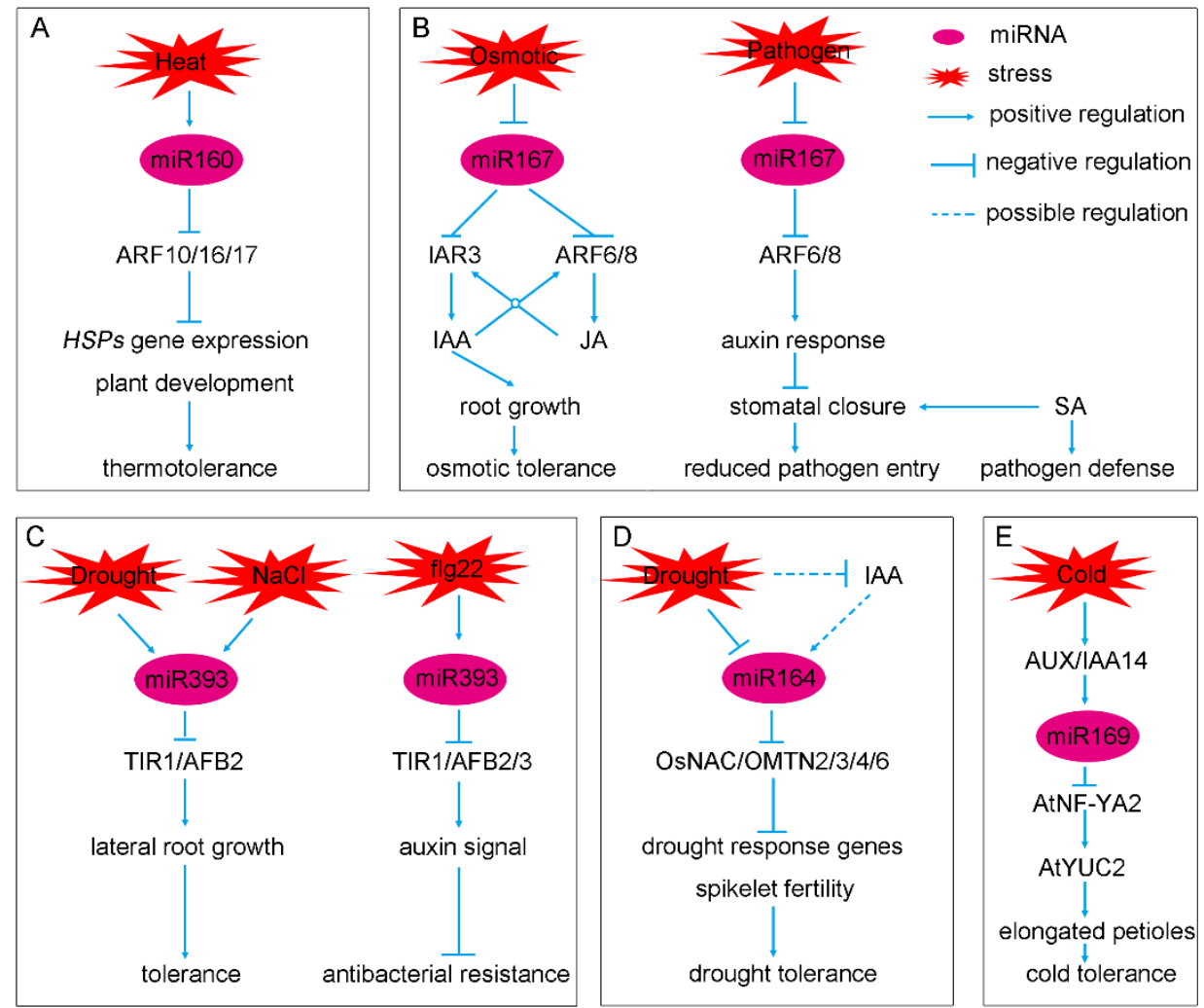

Figure 2. miRNA-auxin signal modules are involved in response to abiotic and biotic stresses in Arabidopsis and rice. (A-E) Summary of specific miRNAs in response to various environmental stresses: (A) miR160; (B) miR167; (C) miR393; (D) miR164, and (E) miR169. Abbreviation: HSPs, heat shock proteins; ARF, auxin response factor; IAR3, Indole acetic acid Alanine-Resistant 3; NAC/OMTN, NAC Domain Containing protein in rice; AUX/IAA, Auxin/Indole Acetic Acid; NF-YA2, Nuclear Factor Y subunit A; YUC, Flavin-binding monooxygenase family protein; TIR1/AFB, Transport Inhibitor Response 1/Auxin Signaling F-box Protein; JA, Jasmonic Acid; SA, Salicylic Acid; flg22, 22-amino acid peptide from the $\mathrm{N}$-terminus of eubacterial flagellin.

In rice, OsmiR160 has four potential targets similar to AtARF10 and AtARF16, namely, OsARF8, OsARF10, OsARF18, and OsARF22 [39]. Of them, OsARF18 has the highest similarity to AtARF16. Rice plants expressing an OsmiR160-resistant version of OsARF8 show pleiotropic defects in growth and development, including reduced starch accumulation, dwarf stature and small seeds [39]. Interestingly, the expression of MIR160a and MIR160b is decreased in mOsARF18 plants, which expresses an miR160-resistant version of OsARF18 in transgenic plants, indicating the negative regulation of OsARF18 by OsmiR160 [39] (Figure 1A). OsmiR167 also has four target OsARFs (OsARF6, OsARF12, OsARF17 and OsARF25). The OsmiR167-OsARF8-OsGH3.2 pathway functions in response to exogenous auxin [40]. OsmiR167-guided OsARF12 expression regulates root elongation and iron accumulation in rice [41], while OsmiR167a represses its targets, OsARF12/17/25, to control rice tiller angle by modulating the asymmetric auxin distribution in shoots [42]. Recently, the OsmiR167a-OsARF6-OsAUX3 module has been reported to regulate grain 
length and weight in rice, indicating the OsmiR167a-mediated auxin distribution may be important for rice yield improvement [43]. Overall, miR160 and miR167 may modulate auxin signaling not only through the simple cleavage of ARFs, but also through influencing auxin homeostasis and response during specific developmental processes (Figure 2A).

In addition to Arabidopsis and rice, the roles of miR160 and miR167 in regulating plant growth and stress responses have also been widely investigated in multiple different species, including wheat, maize, and barley (Table 1). Moreover, the vital role of auxin signaling in nodule initiation, primordia development and nodule organogenesis has been systematically investigated [44,45]. Formation of the root nodule in legumes is also regulated by miR160 and miR167 (Table 1). Consistent with the opposing roles of miR160 and miR167 in regulating adventitious root development in Arabidopsis, these two miRNAs function antagonistically to regulate nodule formation and root system architecture in soybean (Glycine max) [46].

Overall, the miR160-miR167-ARF module represents a critical regulatory node that adjusts a wide range of processes in response to different environmental and developmental stimuli, including embryonic development, root initiation, and reproductive organ maturation.

\subsection{The miR390-TAS3-tasiARF Module Is a Regulatory Hub of Auxin Signaling}

In plants, miR390 directs the production of trans-acting small interfering RNAs (tasiRNAs) from the mRNA of trans-acting Sirna 3 (TAS3) to downregulate ARF2/3/4, which are known as tasiARFs $[47,48]$. The miR390/TAS3/ARF system is evolutionarily conserved [48], and miR390 functions as a regulatory hub in the auxin signaling pathway through: (i) transcription of MIR390a and MIR390b induced by exogenous auxin in a dosedependent manner in seedling roots [49]; (ii) miR390 initiating the biosynthesis of tasiARFs from TAS3 mRNA, which then cleaves AtARF2/3/4 mRNA [50-52]; (iii) ARF3 and ARF4 positively or negatively regulating the accumulation of MIR390a [51]; and (iv) AtARF5 directly binding to the auxin response elements (AuxREs) of the MIR390 promoter and positively regulating its transcription [53] (Figure 1B). In roots, miR390 is specifically expressed at the sites of lateral root (LR) initiation and the transit-amplifying compartment of the meristem, where it controls the spatiotemporal expression of tasiRNAs to prompt LR emergence and response to exogenous IAA in the meristem [49,51,53,54]. Impaired tasiARF production results in decreased young LR primordia (stages 1 to 4), while the elevated tasiARFs exhibit increased LR primordia (stages 5 to 7) [51]. In leaves, miR390-derrived tasiARFs move intercellularly to create a small tasiARFs gradient and pattern the abaxial determinant AtARF3. Subsequently, AtARF3 regulates the expression of downstream genes involved in leaf morphogenesis and developmental timing and patterning [51,55,56]. Considering the potential ability of tasiRNAs to move in a non-cell autonomously manner, the miR390-TAS3-tasiARF module may function as a communication signal to determine the spatial expression pattern of AtARF2/3/4 and to precisely control cell elongation and differentiation during organogenesis in response to different environmental conditions.

As a conserved miRNA in plants, the functions of miR390-mediated regulation during plant development, biotic and abiotic stresses have been investigated in different species (Table 1). Interestingly, miR390 plays dual roles in regulating nodulation and in response to salt stress. In Medicago truncatula, overexpression of miR390 results in promoting LR growth but preventing nodule organogenesis, rhizobial infection, and inhibiting the transcription of nodulation genes, while inactivation of the miR390/TAS3 module increases nodulation and rhizobial infection [57]. In Helianthus tuberosus, $100 \mathrm{mM}$ of $\mathrm{NaCl}$ induces the expression of miR390, while $300 \mathrm{mM}$ of $\mathrm{NaCl}$ inhibits the expression of miR390, which alters the salt tolerance [58]. These distinct roles of miR390 in regulating nodulation and salt stress also indicates the regulatory complexity of the miR390-TAS3-tasiARFs module.

In addition, the expression of miR390 is regulated by AtARF3/4/5. Among these ARFs, AtARF5 is not a target of the miR390-TAS3-tasiARF module, suggesting that the accumulation of miR390 is controlled by the auxin level and/or feedback regulation. This also 
implies that the miR390/TAS3/tasiARF module is a hub of the regulatory networks mediating the auxin response [53]. It would be interesting to investigate which ARFs are employed to control the expression of miR390 during different developmental contexts.

\section{3. miR393, a Repressor of Auxin Signaling}

Another conserved miRNA is miR393, which has been discovered in many plants (Table 1). In Arabidopsis, miR393 is encoded by two loci, AtMIR393a and AtMIR393b, and has four known F-box target genes, namely the TIR1/AFB Auxin Receptors 1-3 (TAAR1-3) $[59,60]$. The tir1/afb quadruple mutant exhibits severe developmental defects, indicating the key role of TAAR-dependent auxin signaling [61]. Previous studies have demonstrated that the miR393-TIR1/AFB regulatory module plays a critical role in root system architecture, leaf development, auxin response and plant response to abiotic and biotic stress (Figures $1 \mathrm{C}$ and 2C) [12]. Under salt stress, $\mathrm{NaCl}$ induces miR393 expression and inhibits TIR1/AFB2 via enhancing the transcription of miR393a, and then inhibits LR initiation, emergence and elongation (Figure 2C) [62]. The peptide flg22 derived from Pseudomonas syringae induces the transcription of AtMIR393a and then negatively regulates TIR1/AFB2/3 in plants to confer transcriptional repression and decrease disease sensitivity (Figure 2C) [63]. In aerial organs, AtMIR393b is the predominant source for mature miR393, and miR393 can guide the cleavage of all four TAAR genes [64]. Surprisingly, miR393 also regulates TAAR expression by initiating secondary siRNA biogenesis of AtAFB2/3 (siTAAR) in aerial organs [64]. In addition, exogenous IAA promotes the accumulation of miR393 in aerial organs via inducing the transcription of AtMIR393b, but not AtMIR393a [65]. Overexpression of the miR393-resistant TIR1 (mTIR1) increases the transcription of miR393, indicating a positive regulation of AtTIR1 at the level of miR393 transcripts. Interestingly, a nitrate $\left(\mathrm{NO}_{3}{ }^{-}\right)$signal can directly upregulate the transcription of AtAFB3, although the metabolism of nitrate, ammonium $\left(\mathrm{NH}_{4}{ }^{+}\right)$and glutamine (Gln) positively regulate the transcription of miR393 (Figure 1C). This feed-forward mechanism can reset both miR393 and its target genes to basal levels [66]. Furthermore, MIR393a and MIR393b synergistically function in somatic embryogenesis and response to drought stress by negatively regulating the expression of AtTIR1/AFB2 [67,68].

Similarly, in rice, miR393 is encoded by two loci, OsMIR393a and OsMIR393b [59,69], and the conserved OsTIR1 and OsAFB2 were identified as target genes of miR393 by degradome sequencing [70] and 5'-RACE [71]. Spatial expression analysis by GUS staining showed that OsMIR393a is strongly expressed in the crown and in adventitious roots, but not in the primary root, while OsMIR393b is expressed in the shoot apical meristem, coleoptile tips and stomata cells, but cannot be detected in the roots [72,73]. Overexpression of OsMIR393a and OsMIR393b caused flag leaf inclination, primary/crown root growth and seed germination defects in rice [72,73]. These data in Arabidopsis and rice suggest that the locus-specific regulation of MIR393 transcription provides another layer for modification of the auxin signaling pathway via cleaving the target genes. 
Table 1. Primary/secondary miRNA targets involved in the regulation of auxin signaling in other species.

\begin{tabular}{|c|c|c|c|c|c|}
\hline miRNA & Species & Direct Targets & Secondary Targets & Target Functions & References \\
\hline \multirow{11}{*}{$\operatorname{miR} 160$} & Solanum lycopersicum & SlARF10/17 & & $\begin{array}{l}\text { Ovary patterning; floral organ abscission; lamina outgrowth; } \\
\text { leaf water loss; pathogen defense }\end{array}$ & [74-80] \\
\hline & Glycine max L. & GmARF & & Nodule development & [45] \\
\hline & Hordeum vulgare & $H v A R F 13 / 17$ & & Heat stress & [81] \\
\hline & Triticum aestivum $\mathrm{L}$. & TaARF & & Abiotic stress & [82] \\
\hline & Zea mays L. & ZmARF & & Drought stress & [83] \\
\hline & Gossypium hirsutum & GhARF10/17 & & Heat stress; salt stress & {$[86,87]$} \\
\hline & Dimocarpus longan & DIARF10/16/17 & & Somatic embryogenesis & [88] \\
\hline & Cucumis melo & CmARF10/16/17 & & Aphid resistance & [89] \\
\hline & Medicago truncatula & MeARF10/16/17 & & Nodule number and development & [90] \\
\hline & Manihot esculenta Crantz & MaARF10 & & Pathogen defense & [91] \\
\hline & Prunus persica $\mathrm{L}$. & PpARF17 & & Fruit enlargement & [92] \\
\hline $\operatorname{miR} 164$ & Solanum lycopersicum & SlNAC1 & NA & Pathogen defense & {$[79,80,94]$} \\
\hline $\operatorname{miR} 166$ & Larix leptolepis & LaHDZIPIII & LaNIT & Somatic embryogenesis & [95] \\
\hline \multirow{6}{*}{$\operatorname{miR} 167$} & Solanum lycopersicum & SlARF6/8 & & Pathogen defence & {$[75,79,96,97]$} \\
\hline & Glycine max & GmARF $8 a / 8 b$ & & Nodulation; lateral root development & [46] \\
\hline & Cucumis melo & CmARF6/8 & & Aphid resistance & [89] \\
\hline & Hordeum vulgare & HvARF8 & & Heat stress & [81] \\
\hline & Populus spp. & PeARF8 & & Adventitious rooting & [98] \\
\hline & Nicotiana tabacum $\mathrm{L}$. & NtARF6/8 & & Phosphorus starvation & [99] \\
\hline
\end{tabular}


Table 1. Cont.

\begin{tabular}{|c|c|c|c|c|c|}
\hline miRNA & Species & Direct Targets & Secondary Targets & Target Functions & References \\
\hline \multirow{9}{*}{$\operatorname{miR390}$} & Zea mays & NA & NA & Drought stress & [83] \\
\hline & Dimocarpus longan & DITAS3 & tasiDlARF3/ARF4 & Somatic embryogenesis & [88] \\
\hline & Cucumis melo & NA & tasiCmARF & Aphids resistance & [89] \\
\hline & Medicago truncatula & MeTAS3 & tasiMeARF2/3/4 & Nodulation; lateral root growth & [57] \\
\hline & Mimulus lewisii & MITAS3 & tasiMlARF3/4 & Corolla tube formation & [100] \\
\hline & Physcomitrella patens & PpTAS3 & tasiPpARF & Developmental timing & [101] \\
\hline & B. oleracea L. var. italica & BoTAS3 & tasiBoARF2/3/4 & Lateral root & [102] \\
\hline & Populus spp. & NA & tasiPsARF3.1/3.2/4 & Salt stress & [103] \\
\hline & Nicotiana tabacum $\mathrm{L}$. & NA & tasiNtARF & Manduca sexta resistance & [104] \\
\hline \multirow{8}{*}{ miR393 } & Glycine max & GmTIR1/AFB3 & & Nodulation & [105] \\
\hline & Hordeum vulgare & HvTIR1/AFB & & Aluminum stress & [106] \\
\hline & Zea mays & ZmTIR1/AFB & & Drought stress & [83] \\
\hline & Cucumis melo & TIR1/AFB2 & & Aphids resistance & [89] \\
\hline & Manihot esculenta Crantz & MaTIR1 & & Pathogen defence & [91] \\
\hline & Prunus persica $\mathrm{L}$. & PpAFB2 & & Fruit enlargement & [92] \\
\hline & Malus $\times$ domestica Borkh. & MdTIR1A & & Adventitious root formation & [108] \\
\hline & Panicum virgatum $\mathrm{L}$. & PvTIR1/AFB1/2/3 & & Cold stress; tillering & [109] \\
\hline miR1153-y & Triticum aestivum. & TaGH3.7 & & Post-mowing regeneration & [110] \\
\hline $\operatorname{miRN} 43$ & Litchi chinensis Sonn. & LcARF9 & & Fruit abscission & [111] \\
\hline
\end{tabular}

NA: information not available. 
Additionally, the roles of miR393 in regulating both normal plant developmental processes, such as nodulation, adventitious root formation, leaf morphogenesis and fruit development, and the response to different environmental stresses, including aluminum stress, drought stress, cold stress and aphid infection, have been widely studied in different species (Table 1). However, due to a lack of a knockout mutant of MIR393, the exact roles of miR393 in plant development and stress responses still need more investigation.

\section{4. miR164 and miR169, Two Modulators of Auxin Signaling}

The miR164 family is comprised of three members (miR164a/b/c) in Arabidopsis but six members (miR164a/b/c/d/e/f) in rice [112-114]. The miR164 molecules guide the cleavage of mRNAs encoding NAC transcription factors [112,115]. AtNAC1 promotes LR development through transduction of the auxin signal downstream of AtTIR1 [115,116]. Overexpression of AtNAC1 can restore LR formation in Attir1, and antisense of AtNAC1 can block AtTIR1-induced LR development [115]. Exogenous IAA induces the transcription of AtMIR164, which disappears in the mutants auxin resistant 1/2 (axr1/2) and tir1 [116]. AtmiR164 also functions as a hub in regulating leaf differentiation and age-dependent cell death $[113,117]$ and functions downstream of AtTCP3, cooperating with the auxin signaling components AtSAUR and AtIAA3 to inhibit the expression of AtCUC1/2 to regulate leaf differentiation [117]. The miR164, AtNAC2 and AtEIN2 form a small regulatory loop for age-dependent cell death in leaves, with the AtEIN2 inhibiting the transcription of AtmiR164 and promoting that of AtNAC2, while AtmiR164 guides the cleavage of AtNAC2 mRNA [113] (Figure 1D). Furthermore, the conserved target genes of miR164 in rice, OsNAC/MTN2/3/4/6, are reported to negatively regulate the drought stress response via miR164-mediated cleavage (Figure 2D). In tomato, miR164 is also involved in the response to viral infection via cleavage of SINAC1 [79,97], although it remains unclear if this involves auxin signaling [112]. Taken together, miR164 may be a modulator in NAC-dependent auxin signaling, where auxin prompts the generation of miR164, which then can clear NAC mRNA to downregulate the auxin signal [116].

The fact that miR169 can respond to cold stress was found through a genome-wide expression analysis in wild-type and solitary root 1 (Atslr1; a knockout of Aux/IAA14) [118]. Further gene expression analysis showed that AtIAA14 positively regulates the transcription of the miR169 precursor AtMIR169 [118]. Moreover, the AtmiR169 target gene, AtNF-YA2, directly binds to the promoters of flowering time (FT) and the auxin biosynthesis gene AtYUC2 in response to ambient temperature [119] (Figure 2E). Hence, the auxinAux/IAA14-miR169 module might constitute a simple regulatory loop to control the free IAA content and then auxin signal transduction in response to temperature stress (Figure 2E). It is therefore necessary to clarify the exact function of miR164 in temperature stress and/or developmental processes using an miR164 knockout mutant.

\section{5. miR847, an Activator of Auxin Signaling}

While miR847 is a low-abundance miRNA, and its accumulation cannot be detected under normal conditions [46], a rapid induction of miR847 is observed upon auxin treatment, and this induction disappears in Attir1 and Ataxr1-3 mutants, demonstrating that miR847 functions downstream of AtTIR1 [46]. Deep sequencing results show that the miR847coding gene, AtMIR847, is an orthologous conserved locus in the Arabidopsis lineage [120]. A 5' RACE assay demonstrated the miR847-mediated cleavage of AtIAA28 mRNA. Phenotypic analysis in lines overexpressing or carrying a mutation of miR847 and AtIAA28 showed that miR847 positively regulates aerial lateral organ development, LR development, meristematic competence and cell proliferation by de-repressing the AtIAA28-dependent auxin signaling pathway (Figure 1E) [46]. The miR847-IAA28 module is concurrent with proteasome-dependent degradation of IAA28 in response to development-induced auxin content alteration and may offer a more precise switch to regulate the IAA28-dependent auxin signaling cascades. 


\section{6. miR156, miR165 and miR166, a New Mode of Action for Regulators of Auxin Homeostasis} and Signaling

Except for the miRNAs that directly regulate the auxin signaling pathway as mentioned above, there are other miRNAs that directly regulate the auxin content and indirectly regulate auxin responses, e.g., miR156, miR165 and miR166 (Figure 1F,G). In rice, OsmiR156 guides the cleavage of Squamosa Promoter Binding Protein-like 7 (OsSPL7), while OsSPL7 can directly bind to the promoter of OsGH3.8, which catalyzes the ATP-dependent formation of IAA-amino acid conjugates [121,122]. Overexpression of OsGH3.8 in miR156overexpression (miR156f-OE) lines can partially complement the developmental defects observed in miR156OE plants, e.g., fewer tillers and increased plant height, indicating that miR156f/SPL7 can directly control OsGH3.8 to regulate plant growth and development (Figure 1F) [122]. In addition, miR165 and miR166 are also reported to regulate auxin accumulation through the activation of AtYUC1/4/10 by the transcription factors Phabulosa/Phavoluta (PHB/PHV) and Leafy Cotyledon2 (LEC2) in Arabidopsis somatic embryogenesis (Figure 1G) [34]. The transcription of AtLEC2 is also upregulated by AtARF10/16, the targets of miR160, indicating a complex regulation of miR160, miR165 and miR166 in controlling somatic embryogenesis (Figure 1A,G). In addition, miR166 in Larix leptolepis is also reported to inhibit the transcription of LaNIT (an auxin biosynthetic gene) and LaARF1/2 through LaHDZIPIII during somatic embyro germination (Table 1) [95]. More studies are still needed to clarify the role of these three miRNAs, including creating knockout mutants of the encoding gene.

\subsection{Non-Conserved miRNA-Auxin Module in Plants}

As mentioned above, the conserved miRNAs, including miR160, miR167, miR390 and miR393, have been extensively investigated in Arabidopsis, rice, tomato, maize, potato, and barley (Figures 1 and 2; Table 1). In addition, there have been some non-conserved miRNAs reported to regulate auxin signaling. During post-mowing regeneration in winter wheat, miR1153-y induces the specific cleavage of TaGH3.7, indicating the potential role of miR1153-y in auxin signaling $[95,110]$. In litchi (Litchi chinensis Sonn.), a novel miRNA-ARF (miRN43-ARF9) regulatory pathway has been discovered, implying that species-specific miRNA may function in the auxin signaling pathway [111]. Another study shows that a long noncoding RNA (lncRNA354) functions as a competitor of GhmiR160b to regulate GhARF17/18 genes under salt stress in upland cotton, suggesting that endogenous RNA in other species may also play roles in regulating miRNA-mediated auxin signaling [87]. Taken together, further studies on different plant species grown in different environments are necessary to identify and investigate new miRNA-auxin signaling modules, which will extend our understanding of the regulation and function of miRNA and auxin signaling.

\section{The Crosstalk of Auxin, miRNA and Other Hormones during Plant Development and Stress Responses}

Auxin controls most developmental stages and stress responses in plants, and the communication between auxin and the other phytohormones (ethylene, abscisic acid, jasmonic acid, cytokinin, etc.) is critical to these processes. Although it is clear that there is phytohormone crosstalk, only a few mediators have been investigated thus far, including miRNAs [55].

The miRNA is involved in multiple developmental processes, including organs morphogenesis, root growth, leaf development, and stress responses, which is a characteristic common to auxin. Additionally, the cis-elements of phytohormones and stress responses have been identified in many MIR gene promoters [123]. Interestingly, miRNA acts in a non-cell-autonomous manner, and functions as a signal molecule between adjacent tissues even plants [124,125]. Due to their transcriptional regulation by different hormones and their trans-regulation capabilities, miRNAs are excellent candidate mediators for the communication between auxin and other hormones. 
Interaction between auxin signaling and cytokinin $(\mathrm{CK})$ in plant development has been investigated in recent years. For example, AtARF3 directly activates ATP/ADP ISOPENTENYLTRANSFERASE 5 (AtIPT5) to promote shoot regeneration [126], and AtARF5mediated Arabidopsis Response Regulator 5/15 (AtARR5/15) repression is important for maintenance of stem cell niches in shoot apical meristems [127]. Moreover, the interdependence among auxin, miRNA and CK has been identified in miR160-AtARF10-AtARR5 module, in which miR160-directed AtARF10 binds to the AtARR15 promoter and inhibits its transcription, thereby promoting CK response during callus initiation [128] (Figure 3). In addition, overexpression of miR160 in legume increases the sensitivity of roots to CK and attenuates expression of CK-regulated transcription factors associated with nodulation, and then inhibits symbiotic nodule development [45]. As protein families which perceive and transduce auxin and CK signaling respectively contain multiple members, it is possible that some members are involved in both auxin- and CK-dependent processes. Hence, a challenge in future would be revealing the complex interaction among auxin, miRNA and CK during plant growth and development.

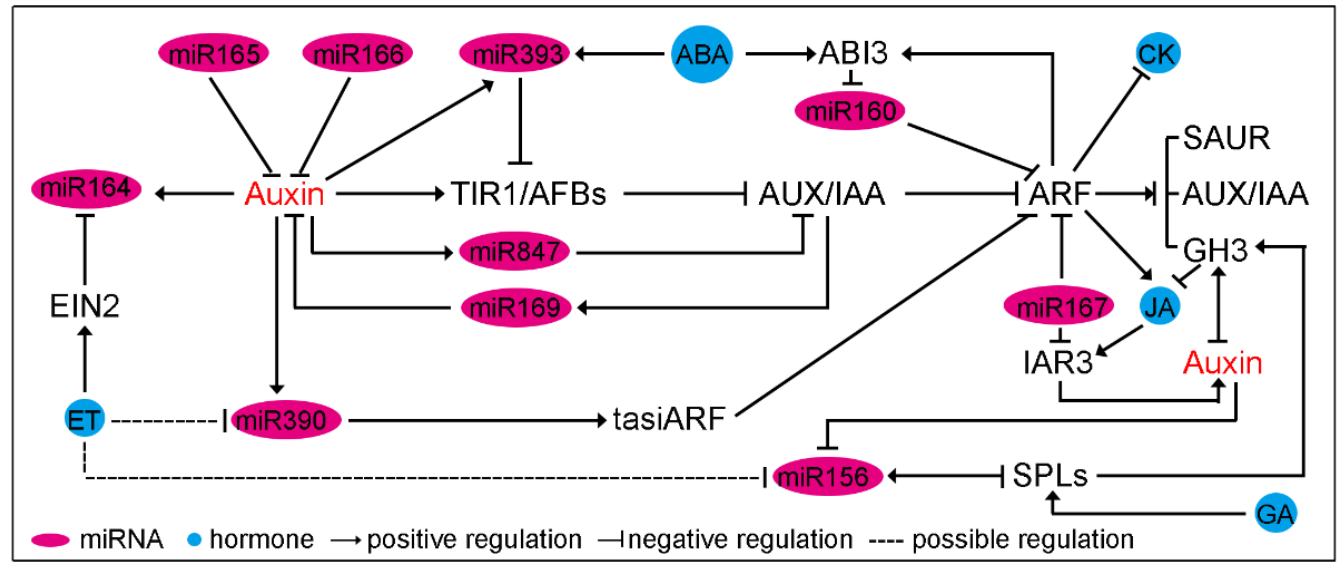

Figure 3. The central role of miRNA-mediated regulation of the crosstalk between auxin and other hormones. Abbreviation: ABA, abscisic acid; CK, cytokinin; ET, ethylene; GA, gibberellin; JA, jasmonic acid.

In addition to $\mathrm{CK}$, the miR160-miR167-ARF module also regulates the expression of several AtGH3 genes, which, in turn, control auxin and jasmonic acid (JA) homeostasis, and modulate adventitious root initiation [26,28]. The miR167 also controls lateral root development via cleavage of AtIAR3, which can hydrolyze IAA conjugates into active IAA and is induced by exogenous JA (Figure 3). These results suggest that miR160 and miR167 function in the crosstalk between auxin and JA during root development through regulating the active IAA and JA contents. Additionally, during flower bud development, the fine-tuned regulation of AtARF6/8, downstream genes of miR167, is essential for the maturation of flowers and JA production [37]; however, the auxin content doesn't change in developing flower buds, indicating that miR167 might function as a modulator to coordinate auxin signaling and JA biosynthesis [37,55]. Moreover, the miR160-ARF10/16$\mathrm{ABI} 3$ regulatory loop is also essential for seed dormancy, seed germination, and somatic embryogenesis [27,31-33]. AtARF10/16 can directly bind to the AtABI3 promoter and enhance ABA-mediated seed dormancy, while the AtABI3 inhibits the transcription of AtMIR160b (Figure 3). Overall, the miR160-miR167-ARF module functions as a potent regulatory node to integrate auxin, $\mathrm{CK}, \mathrm{ABA}$ and JA signaling pathways. Such a regulation appears in a wide range of developmental processes in plants.

In addition to miR160, miR393 is also a mediator of ABA-to-auxin unidirectional signaling. Under drought stress, the increased ABA promotes the transcription of MIR393 and represses auxin signaling via the downregulation of AtTIR1/AFB2 (Figure 3) [65]. In addition, miR393 mediates downregulation of $A t T I R 1 / A F B 2 / 3$ in response to bacterial 
flagellin (Figure 2C) [63]. Considering the critical role of ABA in biotic stress responses, the ABA-miR393-auxin signaling pathway may be triggered by a bacterial infection via increasing the ABA level [55]. The ABA-miR393-auxin signaling pathway might constitute an important response pathway under biotic and abiotic stresses.

Besides ABA and JA, ethylene (ET) is involved in regulating auxin/miRNAs signaling via inhibiting the transcription of miR156, miR164 and miR390. The miR156-SPL module functions as a hinge to integrate multiple phytohormones, including auxin, gibberellin (GA), and ET, in floral transition and lateral organ development [55]. In rice root, miR156 promotes IAA accumulation via SPL7-mediated transcriptional inhibition of OsGH3.8 [122]. Interestingly, auxin treatment decreases the accumulation of miR156 in Arabidopsis roots [51], indicating that the auxin-miR156-SPL module might affect root development via precise control of free IAA content. Additionally, miR156 is also involved in GA-dependent floral transition in Arabidopsis [129]. During floral transition, the DELLA protein, a transcriptional repressor of GA signaling, can interact with and repress SPL protein activity [129]. The increased GA induces the degradation of DELLA and activates the SPL protein, subsequently regulating miR156 (Figure 3) [129,130]. Meanwhile, ET regulates GA-dependent DELLA degradation in Arabidopsis to inhibit miR156 transcription in tomato fruit [131,132]. Together, these results suggest that the miR156-SPL module might coordinate GA, ET and auxin for the modulation of the vegetative-phase transition and lateral organ development in response to different environmental conditions.

The expression of miR164 is gradually repressed by AtEIN2, which subsequently de-represses $A t N A C 2$ during leaf aging [133]. Moreover, the decreased JA level could restore the ET sensitivity of ein 2 and coil (a JA receptor mutant) mutants, suggesting the indirect regulation of miR164 by JA $[133,134]$. Unlike the miRNA mentioned above, miR390 is only slightly downregulated by ET in Medicago root, suggesting that miR390 might participate in the crosstalk of different hormones via the downregulation of its target genes, ARF2/3/4 [55].

With the growing number of studies on the interaction of miRNA and hormone signaling, the number of known target genes of miRNAs involved in different hormone signaling continues to increase. In addition to the hormones described above, new discoveries of miRNA-mediated interactions between auxin and other hormones, including brassinosteroid (BR), CK, salicylic acid (SA), and strigolactones, will deepen our understanding of the crosstalk between auxin and other hormones and make possible the application of miRNAs for crop improvement.

\section{Concluding Remarks}

In plants, auxin plays a central role in growth and development as well as responses to abiotic and biotic stresses [2,3,135-137]. Precise regulation of auxin homeostasis and its signaling is extremely critical. In the last two decades, different miRNAs have emerged as master modulators of the auxin response pathway by affecting its biosynthesis, metabolism, distribution, and perception [138].

The control of auxin responses by miRNAs occurs mostly downstream of the TIR1/AFBs by regulating the expression of ARFs and AUX/IAAs, therefore affecting only part of the auxin-regulated processes. Interestingly, auxin and miRNAs independently regulate the target ARF levels when controlling the development of aerial organs and LRs. In addition, some miRNA families (e.g., miR167 and miR393) have been found to act upstream by regulating genes involved in auxin biosynthesis, metabolism and perception. Therefore such miRNAs play a more crucial role in controlling the auxin response. Hence, miRNA-auxin signaling regulatory modules provide additional layers of modulation of auxin signaling. Moreover, miR390-derived tasiARFs move intercellularly to create a small RNA gradient, which can pattern the abaxial determinant AtARF3 during leaf development [139]. Therefore, deeper investigation of the function of miRNAs will enhance our understanding of the precise regulation of auxin signaling during plant growth and development. 
Although there have been great advances in the study of miRNA-mediated auxin signaling, some questions still need to be further investigated:

(i) How do plants integrate all these developmental signals or stress responses to control the levels of the individual miRNAs-auxin signaling module?

As mentioned above, we have known that plants employ different miRNAs and then their targets in response to different developmental timing and various stress signals; however, it is still unknown how plants precisely control this process. A deeper understanding of the regulatory mechanism(s) will allow us to choose appropriate targets for modulating agriculturally important traits.

(ii) Which lineage-, species- and tissue-specific miRNA molecules are also involved in regulating auxin responses?

As different environments shape different plants, the plants will evolve the specific miRNAs in response; however, previous studies have mainly focused on the functions of conserved miRNAs. Therefore, it would be valuable to evaluate the role of lineage-, species- and tissue-specific miRNAs to complement our view and to determine how broadly miRNA-dependent genetic networks could influence the auxin signaling in different species.

(iii) How can we use miRNA-auxin modules to create tolerance to stresses and/or highyield crops?

Because of the extensive regulation of auxin signaling by miRNAs during plant growth and in response to stresses, miRNAs have been considered as good targets for the genetic improvement of crops [140]. Generally, a given miRNA has different roles due to its multiple targets. Hence, it is necessary to make sure that only the target trait (but not other important traits) could be modified before it can be used for plant improvement. Some strategies have been applied to transgenic experiments, including artificial miRNAs, artificial tasiRNAs, artificial target mimics, and overexpression of miRNA-resistant targets. Additionally, CRISPR-Cas9 technology has been used for improvement of crop agronomic traits [141-146]. Undoubtedly, with the development of transgenic technologies, miRNAbased breeding strategies will offer a wide range of application scenarios.

Author Contributions: P.L. and D.D. drafted, wrote, and edited this review. L.W., J.Y., Y.L. and W.S. participated in the discussion of this review. All authors have read and agreed to the published version of the manuscript.

Funding: This work was supported by the grants from the Scientific research start-up funds for openly-recruited doctors of Gansu Agricultural University (2017RCZX-26), the Chinese National Science Foundation (32030099 and 31601823) and the Natural Science Foundation for Excellent Young Scholars of Jiangsu Province of China (BK20190108).

Institutional Review Board Statement: Not applicable.

Informed Consent Statement: Not applicable.

Data Availability Statement: Not applicable.

Conflicts of Interest: The authors declare no conflict of interest.

\section{References}

1. Báez, R.R.; Nemhauser, J.L. Expansion and innovation in auxin signaling: Where do we grow from here? Development 2021, 148, dev187120. [CrossRef]

2. Di, D.-W.; Li, G.; Sun, L.; Wu, J.; Wang, M.; Kronzucker, H.J.; Fang, S.; Chu, J.; Shi, W. High ammonium inhibits root growth in Arabidopsis thaliana by promoting auxin conjugation rather than inhibiting auxin biosynthesis. J. Plant Physiol. 2021, $261,153415$. [CrossRef]

3. Di, D.-W.; Sun, L.; Zhang, X.; Li, G.; Kronzucker, H.J.; Shi, W. Involvement of auxin in the regulation of ammonium tolerance in rice (Oryza sativa L.). Plant Soil 2018, 432, 373-387. [CrossRef]

4. Mano, Y.; Nemoto, K. The pathway of auxin biosynthesis in plants. J. Exp. Bot. 2012, 63, 2853-2872. [CrossRef]

5. Sauer, M.; Robert, S.; Kleine-Vehn, J. Auxin: Simply complicated. J. Exp. Bot. 2013, 64, 2565-2577. [CrossRef] 
6. Simon, S.; Petrasek, J. Why plants need more than one type of auxin. Plant Sci. 2011, 180, 454-460. [CrossRef]

7. Korasick, D.A.; Enders, T.A.; Strader, L.C. Auxin biosynthesis and storage forms. J. Exp. Bot. 2013, 64, 2541-2555. [CrossRef]

8. Wang, R.H.; Estelle, M. Diversity and specificity: Auxin perception and signaling through the TIR1/AFB pathway. Curr. Opin. Plant Biol. 2014, 21, 51-58. [CrossRef]

9. Villalobos, L.I.A.C.; Lee, S.; De Oliveira, C.; Ivetac, A.; Brandt, W.; Armitage, L.; Sheard, L.B.; Tan, X.; Parry, G.; Mao, H.; et al. A combinatorial TIR1/AFB-Aux/IAA co-receptor system for differential sensing of auxin. Nat. Chem. Biol. 2012, 8, 477-485. [CrossRef]

10. Goda, H.; Sasaki, E.; Akiyama, K.; Maruyama-Nakashita, A.; Nakabayashi, K.; Li, W.; Ogawa, M.; Yamauchi, Y.; Preston, J.; Aoki, K.; et al. The AtGenExpress hormone and chemical treatment data set: Experimental design, data evaluation, model data analysis and data access. Plant J. 2008, 55, 526-542. [CrossRef]

11. Chapman, E.J.; Estelle, M. Mechanism of auxin-regulated gene expression in plants. Annu. Rev. Genet. 2009, 43, 265-285. [CrossRef]

12. Jodder, J. miRNA-mediated regulation of auxin signaling pathway during plant development and stress responses. J. Biosci. 2020, 45, 91. [CrossRef]

13. Matías, B.; Manuel, D.J.; Antonella, F.; Palatnik, J.F. ARF2 represses expression of plant GRF transcription factors in a complementary mechanism to microRNA miR396. Plant Physiol. 2021, 185, 1798-1812.

14. Li, M.; Yu, B. Recent advances in the regulation of plant miRNA biogenesis. RNA Biol. 2021, 18, 2087-2096. [CrossRef]

15. Wang, J.; Mei, J.; Ren, G. Plant microRNAs: Biogenesis, homeostasis, and degradation. Front Plant Sci. 2019, 10, 360. [CrossRef]

16. Mallory, A.C.; Elmayan, T.; Vaucheret, H. MicroRNA maturation and action-the expanding roles of ARGONAUTEs. Curr. Opin. Plant Biol. 2008, 11, 560-566. [CrossRef]

17. Li, M.; Yu, H.; Liu, K.; Yang, W.; Zhou, B.; Gan, L.; Li, S.; Zhang, C.; Yu, B. Serrate-Associated Protein 1, a splicing-related protein, promotes miRNA biogenesis in Arabidopsis. New Phytol. 2021, 232, 1959-1973. [CrossRef]

18. Yang, G.; Li, Y.; Wu, B.; Zhang, K.; Gao, L.; Zheng, C. MicroRNAs transcriptionally regulate promoter activity in Arabidopsis thaliana. J. Integr. Plant Biol. 2019, 61, 1128-1133. [CrossRef]

19. Zhang, B.; Pan, X.; Anderson, T.A. Identification of 188 conserved maize microRNAs and their targets. FEBS Lett. 2006, 580, 3753-3762. [CrossRef]

20. Lu, S.; Sun, Y.; Shi, R.; Clark, C.; Li, L.; Chiang, V. Novel and mechanical stress-responsive microRNAs in Populus trichocarpa that are absent from Arabidopsis. Plant Cell 2005, 17, 2186-2203. [CrossRef]

21. Sanan-Mishra, N.; Kumar, V.; Sopory, S.K.; Mukherjee, S.K. Cloning and validation of novel miRNA from basmati rice indicates cross talk between abiotic and biotic stresses. Mol. Genet. Genom. 2009, 282, 463-474. [CrossRef]

22. Zhang, B.-H.; Pan, X.-P.; Wang, Q.-L.; Cobb, G.P.; Anderson, T.A. Identification and characterization of new plant microRNAs using EST analysis. Cell Res. 2005, 15, 336-360. [CrossRef]

23. Di, D.-W.; Zhang, C.; Guo, G.-Q. Involvement of secondary messengers and small organic molecules in auxin perception and signaling. Plant Cell Rep. 2015, 34, 895-904. [CrossRef]

24. Dubey, S.; Saxena, S.; Chauhan, A.S.; Mathur, P.; Chakrabaroty, D. Identification and expression analysis of conserved microRNAs during short and prolonged chromium stress in rice (Oryza sativa). Environ. Sci. Pollut. Res. Int. 2020, 27, 380-390. [CrossRef]

25. Singh, S.; Singh, A. A prescient evolutionary model for genesis, duplication and differentiation of MIR160 homologs in Brassicaceae. Mol. Genet. Genom. 2021, 296, 985-1003. [CrossRef]

26. Gutierrez, L.; Bussell, J.D.; Pacurar, D.I.; Schwambach, J.; Pacurar, M.; Bellini, C. Phenotypic plasticity of adventitious rooting in Arabidopsis is controlled by complex regulation of AUXIN RESPONSE FACTOR transcripts and microRNA abundance. Plant Cell 2009, 21, 3119-3132. [CrossRef]

27. Liu, P.-P.; Montgomery, T.A.; Fahlgren, N.; Kasschau, K.D.; Nonogaki, H.; Carrington, J.C. Repression of AUXIN RESPONSE FACTOR10 by microRNA160 is critical for seed germination and post-germination stages. Plant J. 2007, 52, 133-146. [CrossRef]

28. Mallory, A.C.; Bartel, D.P.; Bartel, B. MicroRNA-directed regulation of Arabidopsis AUXIN RESPONSE FACTOR17 is essential for proper development and modulates expression of early auxin response genes. Plant Cell 2005, 17, 1360-1375. [CrossRef]

29. Wang, J.-W.; Wang, L.-J.; Mao, Y.-B.; Cai, W.-J.; Xue, H.-W.; Chen, X.-Y. Control of root cap formation by microRNA-targeted auxin response factors in Arabidopsis. Plant Cell 2005, 17, 2204-2216. [CrossRef]

30. Wu, M.-F.; Tian, Q.; Reed, J.W. Arabidopsis microRNA167 controls patterns of ARF6 and ARF8 expression, and regulates both female and male reproduction. Development 2006, 133, 4211-4218. [CrossRef]

31. Chen, B.; Martijn, F.; Dekkers, B.; Lena, M.; Wilma, V.; Angenent, G.C.; Zhao, Y.; Kim, B. ABA signalling promotes cell totipotency in the shoot apex of germinating embryos. J. Exp. Bot. 2021, 72, 6418-6436. [CrossRef]

32. Liu, X.; Zhang, H.; Zhao, Y.; Feng, Z.; Li, Q.; Yang, H.-Q.; Luan, S.; Li, J.; He, Z.-H. Auxin controls seed dormancy through stimulation of abscisic acid signaling by inducing ARF-mediated ABI3 activation in Arabidopsis. Proc. Natl. Acad. Sci. USA 2013, 110, 15485-15490. [CrossRef]

33. Tian, R.; Wang, F.; Zheng, Q.; Niza, V.M.A.G.E.; Downie, A.B.; Perry, S.E. Direct and indirect targets of the Arabidopsis seed transcription factor ABSCISIC ACID INSENSITIVE3. Plant J. 2020, 103, 1679-1694. [CrossRef]

34. Wojcik, A.M.; Nodine, M.D.; Gaj, M.D. miR160 and miR166/165 contribute to the LEC2-mediated auxin response involved in the somatic embryogenesis induction in Arabidopsis. Front. Plant Sci. 2017, 8, 2024. [CrossRef] 
35. Lin, J.-S.; Kuo, C.-C.; Yang, I.-C.; Tsai, W.-A.; Shen, Y.-H.; Lin, C.-C.; Liang, Y.-C.; Li, Y.-C.; Kuo, Y.-W.; King, Y.-C.; et al. MicroRNA160 modulates plant development and heat shock protein gene expression to mediate heat tolerance in Arabidopsis. Front. Plant Sci. 2018, 9, 68. [CrossRef]

36. Kinoshita, N.; Wang, H.; Kasahara, H.; Liu, J.; MacPherson, C.; Machida, Y.; Kamiya, Y.; Hannah, M.A.; Chua, N.-H. IAA-Ala resistant 3, an evolutionarily conserved target of miR167, mediates Arabidopsis root architecture changes during high osmotic stress. Plant Cell 2012, 24, 3590-3602. [CrossRef]

37. Nagpal, P.; Ellis, C.M.; Weber, H.; Ploense, S.E.; Barkawi, L.S.; Guilfoyle, T.J.; Hagen, G.; Alonso, J.M.; Cohen, J.D.; Farmer, E.E.; et al. Auxin response factors ARF6 and ARF8 promote jasmonic acid production and flower maturation. Development 2005, 132, 4107-4118. [CrossRef]

38. Caruana, J.C.; Dhar, N.; Raina, R. Overexpression of Arabidopsis microRNA167 induces salicylic acid-dependent defense against Pseudomonas syringae through the regulation of its targets ARF6 and ARF8. Plant Direct 2020, 4, e00270. [CrossRef]

39. Huang, J.; Li, Z.Y.; Zhao, D.Z. Deregulation of the OsmiR160 target gene OsARF18 causes growth and developmental defects with an alteration of auxin signaling in rice. Sci. Rep. 2016, 6, 29938. [CrossRef]

40. Yang, J.; Han, S.; Yoon, E.K.; Lee, W.S. Evidence of an auxin signal pathway, microRNA167-ARF8-GH3, and its response to exogenous auxin in cultured rice cells. Nucleic Acids Res. 2006, 34, 1892-1899. [CrossRef]

41. Qi, Y.; Wang, S.; Shen, C.; Zhang, S.; Chen, Y.; Xu, Y.; Liu, Y.; Wu, Y.; Jiang, D. OsARF12, a transcription activator on auxin response gene, regulates root elongation and affects iron accumulation in rice (Oryza sativa). New Phytol. 2012, 193, 109-120. [CrossRef]

42. Li, Y.; Li, J.; Chen, Z.; Wei, Y.; Qi, Y.; Wu, C. OsmiR167a-targeted auxin response factors modulate tiller angle via fine-tuning auxin distribution in rice. Plant Biotechnol. J. 2020, 18, 2015-2026. [CrossRef]

43. Qiao, J.; Jiang, H.; Lin, Y.; Shang, L.; Wang, M.; Li, D.; Fu, X.; Geisler, M.; Qi, Y.; Gao, Z.; et al. A novel miR167a-OsARF6-OsAUX3 module regulates grain length and weight in rice. Mol. Plant 2021, 14, 1683-1698. [CrossRef]

44. Suzaki, T.; Yano, K.; Ito, M.; Umehara, Y.; Suganuma, N.; Kawaguchi, M. Positive and negative regulation of cortical cell division during root nodule development in Lotus japonicus is accompanied by auxin response. Development 2012, 139, 3997-4006. [CrossRef]

45. Turner, M.; Nizampatnam, N.R.; Baron, M.; Coppin, S.; Damodaran, S.; Adhikari, S.; Arunachalam, S.P.; Yu, O.; Subramanian, S. Ectopic expression of miR160 results in auxin hypersensitivity, cytokinin hyposensitivity, and inhibition of symbiotic nodule development in soybean. Plant Physiol. 2013, 162, 2042-2055. [CrossRef]

46. Wang, Y.; Li, K.; Chen, L.; Zou, Y.; Liu, H.; Tian, Y.; Li, D.; Wang, R.; Zhao, F.; Ferguson, B.J.; et al. MicroRNA167-directed regulation of the auxin response factors GmARF8a and GmARF8b is required for soybean nodulation and lateral root development. Plant Physiol. 2015, 168, 984-999. [CrossRef]

47. Allen, E.; Xie, Z.; Gustafson, A.M.; Carrington, J.C. microRNA-directed phasing during trans-acting siRNA biogenesis in plants. Cell 2005, 121, 207-221. [CrossRef]

48. Xia, R.; Xu, J.; Meyers, B.C. The emergence, evolution, and diversification of the miR390-TAS3-ARF pathway in land plants. Plant Cell 2017, 29, 1232-1247. [CrossRef]

49. Yoon, E.K.; Yang, J.H.; Lee, W.S. Auxin and abscisic acid responses of auxin response factor 3 in Arabidopsis lateral root development. J. Plant Biol. 2010, 53, 150-154. [CrossRef]

50. de Felippes, F.F.; Marchais, A.; Sarazin, A.; Oberlin, S.; Voinnet, O. A single miR390 targeting event is sufficient for triggering TAS3-tasiRNA biogenesis in Arabidopsis. Nucleic Acids Res. 2017, 45, 5539-5554. [CrossRef]

51. Marin, E.; Jouannet, V.; Herz, A.; Lokerse, A.S.; Weijers, D.; Vaucheret, H.; Nussaume, L.; Crespi, M.D.; Maizel, A. miR390, Arabidopsis TAS3 tasiRNAs, and their AUXIN RESPONSE FACTOR Targets Define an Autoregulatory Network Quantitatively Regulating Lateral Root Growth. Plant Cell 2010, 22, 1104-1117. [CrossRef]

52. Williams, L.; Carles, C.C.; Osmont, K.S.; Fletcher, J.C. A database analysis method identifies an endogenous trans-acting shortinterfering RNA that targets the Arabidopsis ARF2, ARF3, and ARF4 genes. Proc. Natl. Acad. Sci. USA 2005, 102, 9703-9708. [CrossRef]

53. Dastidar, M.G.; Scarpa, A.; Magele, I.; Ruiz-Duarte, P.; von Born, P.; Bald, L.; Jouannet, V.; Maizel, A. ARF5/MONOPTEROS directly regulates miR390 expression in the Arabidopsis thaliana primary root meristem. Plant Direct 2019, 3, e00116. [CrossRef]

54. Yoon, E.K.; Yang, J.H.; Lim, J.; Kim, S.H.; Kim, S.K.; Lee, W.S. Auxin regulation of the microRNA390-dependent transacting small interfering RNA pathway in Arabidopsis lateral root development. Nucleic Acids Res. 2010, 38, 1382-1391. [CrossRef]

55. Curaba, J.; Singh, M.B.; Bhalla, P.L. miRNAs in the crosstalk between phytohormone signalling pathways. J. Exp. Bot. 2014, 65, 1425-1438. [CrossRef]

56. Hunter, C.; Willmann, M.R.; Wu, G.; Yoshikawa, M.; de la Luz Gutierrez-Nava, M.; Poethig, S.R. Trans-acting siRNA-mediated repression of ETTIN and ARF4 regulates heteroblasty in Arabidopsis. Development 2006, 133, 2973-2981. [CrossRef]

57. Hobecker, K.V.; Reynoso, M.A.; Bustos-Sanmamed, P.; Wen, J.Q.; Mysore, K.S.; Crespi, M.; Blanco, F.A.; Zanetti, M.E. The microRNA390/TAS3 pathway mediates symbiotic nodulation and lateral toot growth. Plant Physiol. 2017, 174, 2469-2486. [CrossRef]

58. Wen, F.-L.; Yue, Y.; He, T.-F.; Gao, X.-M.; Zhou, Z.S.; Long, X.-H. Identification of miR390-TAS3-ARF pathway in response to salt stress in Helianthus tuberosus L. Gene 2020, 738, 144460. [CrossRef]

59. Jones-Rhoades, M.W.; Bartel, D.P. Computational identification of plant MicroRNAs and their targets, including a stress-induced miRNA. Mol. Cell 2004, 14, 787-799. [CrossRef] 
60. Jones-Rhoades, M.W.; Bartel, D.P.; Bartel, B. MicroRNAs and their regulatory roles in plants. Annu. Rev. plant Biol. 2006, 57, 19-53. [CrossRef]

61. Kepinski, S.; Leyser, O. The Arabidopsis F-box protein TIR1 is an auxin receptor. Nature 2005, 435, 446-451. [CrossRef]

62. Iglesias, M.J.; Terrile, M.C.; Windels, D.; Lombardo, M.C.; Bartoli, C.G.; Vazquez, F.; Estelle, M.; Casalongue, C.A. MiR393 regulation of auxin signaling and redox-related components during acclimation to salinity in Arabidopsis. PLoS ONE 2014, 9, e107678.

63. Navarro, L.; Dunoyer, P.; Jay, F.; Arnold, B.; Dharmasiri, N.; Estelle, M.; Voinnet, O.; Jones, J.D.G. A plant miRNA contributes to antibacterial resistance by repressing auxin signaling. Science 2006, 312, 436-439. [CrossRef]

64. Si-Ammour, A.; Windels, D.; Arn-Bouldoires, E.; Kutter, C.; Ailhas, J.; Meins, F.; Vazquez, F. miR393 and secondary siRNAs regulate expression of the TIR1/AFB2 auxin receptor clade and auxin-related development of Arabidopsis leaves. Plant Physiol. 2011, 157, 683-691. [CrossRef]

65. Chen, Z.-H.; Bao, M.-L.; Sun, Y.-Z.; Yang, Y.-J.; Xu, X.-H.; Wang, J.-H.; Han, N.; Bian, H.-W.; Zhu, M.-Y. Regulation of auxin response by miR393-targeted transport inhibitor response protein 1 is involved in normal development in Arabidopsis. Plant Mol. Biol. 2011, 77, 619-629. [CrossRef]

66. Vidal, E.A.; Araus, V.; Lu, C.; Parry, G.; Green, P.J.; Coruzzi, G.M.; Gutierrez, R.A. Nitrate-responsive miR393/AFB3 regulatory module controls root system architecture in Arabidopsis thaliana. Proc. Natl. Acad. Sci. USA 2010, 107, 4477-4482. [CrossRef]

67. Chen, H.; Li, Z.F.; Xiong, L.M. A plant microRNA regulates the adaptation of roots to drought stress. Febs Lett. 2012, 586, 1742-1747. [CrossRef]

68. Wojcik, A.M.; Gaj, M.D. miR393 contributes to the embryogenic transition induced in vitro in Arabidopsis via the modification of the tissue sensitivity to auxin treatment. Planta 2016, 244, 231-243. [CrossRef]

69. Archak, S.; Nagaraju, J. Computational prediction of rice (Oryza sativa) miRNA targets. Genom. Proteom. Bioinf. 2007, 5, 196-206. [CrossRef]

70. Li, Y.-F.; Zheng, Y.; Addo-Quaye, C.; Zhang, L.; Saini, A.; Jagadeeswaran, G.; Axtell, M.J.; Zhang, W.; Sunkar, R. Transcriptomewide identification of microRNA targets in rice. Plant J. 2010, 62, 742-759. [CrossRef]

71. Xia, K.-F.; Wang, R.; Ou, X.-J.; Fang, Z.-M.; Tian, C.-G.; Duan, J.; Wang, Y.-Q.; Zhang, M.-Y. OsTIR1 and OsAFB2 downregulation via OsmiR393 overexpression leads to more tillers, early flowering and less tolerance to salt and drought in rice. PLoS ONE 2012, 7, 364-373. [CrossRef]

72. Bian, H.W.; Xie, Y.K.; Guo, F.; Han, N.; Ma, S.; Zeng, Z.; Wang, J.; Yang, Y.; Zhu, M. Distinctive expression patterns and roles of the miRNA393/TIR1 homolog module in regulating flag leaf inclination and primary and crown root growth in rice (Oryza sativa). New Phytol. 2012, 196, 149-161. [CrossRef]

73. Guo, F.; Han, N.; Xie, Y.; Fang, K.; Yang, Y.; Zhu, M.; Wang, J.; Bian, H. The miR393a/target module regulates seed germination and seedling establishment under submergence in rice (Oryza sativa L.). Plant Cell Environ. 2016, 39, 2288-2302. [CrossRef]

74. Damodharan, S.; Zhao, D.Z.; Arazi, T. A common miRNA160-based mechanism regulates ovary patterning, floral organ abscission and lamina outgrowth in tomato. Plant J. 2016, 86, 458-471. [CrossRef]

75. Feng, J.; Lai, L.; Lin, R.; Jin, C.; Chen, J. Differential effects of Cucumber mosaic virus satellite RNAs in the perturbation of microRNA-regulated gene expression in tomato. Mol. Biol. Rep. 2012, 39, 775-784. [CrossRef]

76. Feng, J.; Lin, R.; Chen, J. Alteration of tomato microRNAs expression during fruit development upon Cucumber mosaic virus and Tomato aspermy virus infection. Mol. Biol. Rep. 2013, 40, 3713-3722. [CrossRef]

77. Jin, W.B.; Wu, F.L.; Xiao, L.; Liang, G.W.; Zhen, Y.X.; Guo, Z.K.; Guo, A.G. Microarray-based analysis of tomato miRNA regulated by Botrytis cinerea. J. Plant Growth Regul. 2012, 31, 38-46. [CrossRef]

78. Liu, X.; Dong, X.; Liu, Z.; Shi, Z.; Jiang, Y.; Qi, M.F.; Xu, T.; Li, T. Repression of ARF10 by microRNA160 plays an important role in the mediation of leaf water loss. Plant Mol. Biol. 2016, 92, 313-336. [CrossRef]

79. Naqvi, A.R.; Haq, Q.M.R.; Mukherjee, S.K. MicroRNA profiling of tomato leaf curl new delhi virus (tolcndv) infected tomato leaves indicates that deregulation of mir159/319 and mir172 might be linked with leaf curl disease. Virol. J. 2010, 7, 281. [CrossRef]

80. Tsushima, D.; Adkar-Purushothama, C.R.; Taneda, A.; Sano, T. Changes in relative expression levels of viroid-specific small RNAs and microRNAs in tomato plants infected with severe and mild symptom-inducing isolates of Potato spindle tuber viroid. J. Gen. Plant Pathol. 2015, 81, 49-62. [CrossRef]

81. Kruszka, K.; Pacak, A.; Swida-Barteczka, A.; Nuc, P.; Alaba, S.; Wroblewska, Z.; Karlowski, W.; Jarmolowski, A.; SzweykowskaKulinska, Z. Transcriptionally and post-transcriptionally regulated microRNAs in heat stress response in barley. J. Exp. Bot. 2014 65, 6123-6135. [CrossRef]

82. Kumar, R.R.; Pathak, H.; Sharma, S.K.; Kala, Y.K.; Nirjal, M.K.; Singh, G.P.; Goswami, S.; Rai, R.D. Novel and conserved heat-responsive microRNAs in wheat (Triticum aestivum L.). Funct. Integr. Genomic 2015, 15, 323-348. [CrossRef]

83. Aravind, J.; Rinku, S.; Pooja, B.; Shikha, M.; Kaliyugam, S.; Mallikarjuna, M.G.; Kumar, A.; Rao, A.R.; Nepolean, T. Identification, characterization, and functional validation of drought-responsive microRNAs in subtropical maize inbreds. Front. Plant Sci. 2017, 8, 941. [CrossRef]

84. Natarajan, B.; Kalsi, H.S.; Godbole, P.; Malankar, N.; Thiagarayaselvam, A.; Siddappa, S.; Thulasiram, H.V.; Chakrabarti, S.K.; Banerjee, A.K. MiRNA160 is associated with local defense and systemic acquired resistance against Phytophthora infestans infection in potato. J. Exp. Bot. 2018, 69, 2023-2036. [CrossRef] 
85. Yang, J.; Zhang, N.; Zhang, J.; Jin, X.; Si, H. Knockdown of MicroRNA160a/b by STTM leads to root architecture changes via auxin signaling in Solanum tuberosum. Plant Physiol. Bioch. 2021, 166, 939-949. [CrossRef]

86. Ding, Y.; Ma, Y.; Liu, N.; Xu, J.; Hu, Q.; Li, Y.; Wu, Y.; Xie, S.; Zhu, L.; Min, L.; et al. microRNAs involved in auxin signalling modulate male sterility under high-temperature stress in cotton (Gossypium hirsutum). Plant J. 2017, 91, 977-994. [CrossRef]

87. Zhang, X.; Shen, J.; Xu, Q.; Dong, J.; Song, L.; Wang, W.; Shen, F. Long noncoding RNA lncRNA354 functions as a competing endogenous RNA of miR160b to regulate ARF genes in response to salt stress in upland cotton. Plant Cell Environ. 2021, 44, 3302-3321. [CrossRef]

88. Lin, Y.; Lin, L.; Lai, R.; Liu, W.; Chen, Y.; Zhang, Z.; XuHan, X.; Lai, Z. MicroRNA390-directed TAS3 cleavage leads to the production of tasiRNA-ARF3/4 during somatic embryogenesis in Dimocarpus longan Lour. Front. Plant Sci. 2015, 6, 1119. [CrossRef]

89. Sattar, S.; Addo-Quaye, C.; Thompson, G.A. miRNA-mediated auxin signalling repression during Vat-mediated aphid resistance in Cucumis melo. Plant Cell Environ. 2016, 39, 1216-1227. [CrossRef]

90. Bustos-Sanmamed, P.; Mao, G.H.; Deng, Y.; Elouet, M.; Khan, G.A.; Bazin, J.; Turner, M.; Subramanian, S.; Yu, O.; Crespi, M.; et al. Overexpression of miR160 affects root growth and nitrogen-fixing nodule number in Medicago truncatula. Funct. Plant Biol. 2013, 40, 1208-1220. [CrossRef]

91. Pinweha, N.; Asvarak, T.; Viboonjun, U.; Narangajavana, J. Involvement of miR160/miR393 and their targets in cassava responses to anthracnose disease. J. Plant Physiol 2015, 174, 26-35. [CrossRef]

92. Shi, M.; Hu, X.; Wei, Y.; Hou, X.; Yuan, X.; Liu, J.; Liu, Y. Genome-wide profiling of small RNAs and degradome revealed conserved regulations of miRNAs on auxin-responsive genes during fruit enlargement in Peaches. Inter. J. Mol. Sci. 2017, 18, 2599. [CrossRef]

93. Wang, Y.; Dai, J.; Chen, R.; Song, C.; Wei, P.; Cai, Y.; Wang, Y.; Han, B. miRNA-based drought regulation in the important medicinal plant Dendrobium huoshanense. J. Plant Growth Regul. 2021, 1-10. [CrossRef]

94. Jin, W.; Wu, F. Characterization of miRNAs associated with Botrytis cinerea infection of tomato leaves. BMC Plant Biol. 2015, 15, 1-14. [CrossRef]

95. Li, Z.-X.; Zhang, L.-F.; Li, W.-F.; Qi, L.-W.; Han, S.-Y. MIR166a affects the germination of somatic embryos in Larixleptolepis by modulating IAA biosynthesis and signaling genes. J. Plant Growth Regul. 2017, 36, 889-896. [CrossRef]

96. Diermann, N.; Matousek, J.; Junge, M.; Riesner, D.; Steger, G. Characterization of plant miRNAs and small RNAs derived from potato spindle tuber viroid (PSTVd) in infected tomato. Biol. Chem. 2010, 391, 1379-1390. [CrossRef]

97. Lang, Q.-L.; Zhou, X.-C.; Zhang, X.-L.; Drabek, R.; Zuo, Z.-X.; Ren, Y.-L.; Li, T.-B.; Chen, J.-S.; Gao, X.-L. Microarray-based identification of tomato microRNAs and time course analysis of their response to Cucumber mosaic virus infection. J. Zhejiang Univ. Sci. 2011, 12, 116-125. [CrossRef]

98. Cai, H.; Yang, C.; Liu, S.; Qi, H.; Wu, L.; Xu, L.A.; Xu, M. MiRNA-target pairs regulate adventitious rooting in Populus: A functional role for miR167a and its target auxin response factor 8. Tree Physiol. 2019, 39, 1922-1936. [CrossRef]

99. Chen, X.; Liu, Z.; Shi, G.; Bai, Q.; Guo, C.; Xiao, K. MIR167a transcriptionally regulates ARF6 and ARF8 and mediates drastically plant Pi-starvation response via modulation of various biological processes. Plant Cell Tiss. Org. 2018, 133, 177-191. [CrossRef]

100. Ding, B.; Xia, R.; Lin, Q.; Gurung, V.; Sagawa, J.; Stanley, L.E.; Strobel, M.; Diggle, P.K.; Meyers, B.C.; Yuan, Y. Developmental genetics of corolla tube formation: Role of the tasiRNA-ARF pathway and a conceptual model. Plant Cell 2020, 32, 3452-3468. [CrossRef]

101. Cho, S.H.; Coruh, C.; Axtell, M.J. miR156 and miR390 regulate tasiRNA accumulation and developmental timing in Physcomitrella patens. Plant Cell 2012, 24, 4837-4849. [CrossRef]

102. He, L.; Wang, Y.; Jia, Y.; Yang, Y.; Wang, C. Ectopic overexpression of bol-miR390a from broccoli (B. oleracea L var. italica) increases lateral branches in Arabidopsis. Plant Growth Regul. 2020, 92, 1-12. [CrossRef]

103. Fu, C.; Shen, H.; Guo, Y.; Leng, L.; Luo, M. The MicroRNA390/TRANS-ACTING SHORT INTERFERING RNA3 module mediates lateral root growth under salt stress via the auxin pathway. Plant Physiol. 2018, 177, 775-791.

104. Pradhan, M.; Rocha, C.; Halitschke, R.; Baldwin, I.T.; Pandey, S.P. microRNA390 modulates Nicotiana attenuata's tolerance response to Manduca sexta herbivory. Plant Direct 2021, 5, e350. [CrossRef]

105. Cai, Z.; Wang, Y.; Zhu, L.; Tian, Y.; Chen, L.; Sun, Z.; Ullah, I.; Li, X. GmTIR1/GmAFB3-based auxin perception regulated by miR393 modulates soybean nodulation. New Phytol. 2017, 215, 672-686. [CrossRef]

106. Bai, B.; Bian, H.; Zeng, Z.H.; Hou, N.; Shi, B.; Wang, J.H.; Zhu, M.Y.; Han, N. miR393-mediated auxin signaling regulation is involved in root elongation inhibition in response to toxic aluminum stress in barley. Plant Cell Physiol. 2017, 58, 426-439. [CrossRef]

107. Xu, J.; Li, J.; Cui, L.; Zhang, T.; Wu, Z.; Zhu, P.; Meng, Y.; Zhang, K.; Yu, X.; Lou, Q.; et al. New insights into the roles of cucumber TIR1 homologs and miR393 in regulating fruit/seed set development and leaf morphogenesis. BMC Plant Biol. 2017, 17, 130. [CrossRef]

108. Li, K.; Wei, Y.; Wang, R.; Mao, J.; Tian, H.; Chen, S.; Li, S.; Tahir, M.M.; Zhang, D. Mdm-MIR393b-mediated adventitious root formation by targeted regulation of MdTIR1A expression and weakened sensitivity to auxin in apple rootstock. Plant Sci. 2021, 308, 110909. [CrossRef]

109. Liu, Y.; Wang, K.; Li, D.; Yan, J.; Zhang, W. Enhanced cold tolerance and tillering in Switchgrass (Panicum virgatum L.) by heterologous expression of Osa-miR393a. Plant Cell Physiol. 2017, 58, 2226-2240. [CrossRef] 
110. Cui, G.; Zhao, M.; Zhang, S.; Wang, Z.; Xi, Y. MicroRNA and regulation of auxin and cytokinin signalling during post-mowing regeneration of winter wheat (Triticum aestivum L.). Plant Physiol. Bioch. 2020, 155, 769-779. [CrossRef]

111. Zhang, Y.; Zeng, Z.; Chen, C.; Li, C.; Xia, R.; Li, J. Genome-wide characterization of the auxin response factor (ARF) gene family of litchi (Litchi chinensis Sonn.): Phylogenetic analysis, miRNA regulation and expression changes during fruit abscission. PeerJ 2019, 7, e6677. [CrossRef]

112. Fang, Y.; Xie, K.; Xiong, L. Conserved miR164-targeted NAC genes negatively regulate drought resistance in rice. J. Exp. Bot. 2014, 65, 2119-2135. [CrossRef]

113. Kim, J.H.; Woo, H.R.; Kim, J.; Lim, P.O.; Lee, I.C.; Choi, S.H.; Hwang, D.; Nam, H.G. Trifurcate feed-forward regulation of age-dependent cell death involving miR164 in Arabidopsis. Science 2009, 323, 1053-1057. [CrossRef]

114. Sunkar, R.; Zhou, X.; Zheng, Y.; Zhang, W.; Zhu, J.-K. Identification of novel and candidate miRNAs in rice by high throughput sequencing. BMC Plant Biol. 2008, 8, 25. [CrossRef]

115. Xie, Q.; Frugis, G.; Colgan, D.; Chua, N.H. Arabidopsis NAC1 transduces auxin signal downstream of TIR1 to promote lateral root development. Gene Dev. 2000, 14, 3024-3036. [CrossRef]

116. Guo, H.-S.; Xie, Q.; Fei, J.-F.; Chua, N.-H. MicroRNA directs mRNA cleavage of the transcription factor NAC1 to downregulate auxin signals for Arabidopsis lateral root development. Plant Cell 2005, 17, 1376-1386. [CrossRef]

117. Koyama, T.; Mitsuda, N.; Seki, M.; Shinozaki, K.; Ohme-Takagi, M. TCP Transcription factors regulate the activities of ASYMMETRIC LEAVES1 and miR164, as well as the auxin response, during differentiation of leaves in Arabidopsis. Plant Cell 2010, 22, 3574-3588. [CrossRef]

118. Aslam, M.; Sugita, K.; Qin, Y.; Rahman, A. Aux/IAA14 regulates microRNA-mediated cold stress response in Arabidopsis roots. Int. J. Mol.Sci. 2020, 21, 8441. [CrossRef]

119. Gyula, P.; Baksa, I.; Toth, T.; Mohorianu, I.; Dalmay, T.; Szittya, G. Ambient temperature regulates the expression of a small set of sRNAs influencing plant development through NF-YA2 and YUC2. Plant Cell Environ. 2018, 41, 2404-2417. [CrossRef]

120. Fahlgren, N.; Jogdeo, S.; Kasschau, K.D.; Sullivan, C.M.; Chapman, E.J.; Laubinger, S.; Smith, L.M.; Dasenko, M.; Givan, S.A.; Weigel, D.; et al. MicroRNA gene evolution in Arabidopsis lyrata and Arabidopsis thaliana. Plant Cell 2010, 22, 1074-1089. [CrossRef]

121. Chen, Q.; Westfall, C.S.; Hicks, L.M.; Wang, S.P.; Jez, J.M. Kinetic basis for the conjugation of auxin by a GH3 family indole-acetic acid-amido synthetase. J. Biol. Chem. 2010, 285, 29780-29786. [CrossRef]

122. Dai, Z.; Wang, J.; Yang, X.; Lu, H.; Miao, X.; Shi, Z. Modulation of plant architecture by the miR156f-OsSPL7-OsGH3.8 pathway in rice. J. Exp. Bot. 2018, 69, 5117-5130. [CrossRef]

123. Zhao, X.; Li, L. Comparative analysis of microRNA promoters in Arabidopsis and rice. Genom. Proteom. Bioinf. 2013, 11, 56-60. [CrossRef]

124. Betti, F.; Ladera-Carmona, M.J.; Weits, D.A.; Ferri, G.; Iacopino, S.; Novi, G.; Svezia, B.; Kunkowska, A.B.; Santaniello, A.; Piaggesi, A.; et al. Exogenous miRNAs induce post-transcriptional gene silencing in plants. Nat. Plants 2021, 7, 1379-1388. [CrossRef]

125. Strzyz, P. microRNA communication in plants. Nat. Rev. Mol. Cell Bio. 2021, 22, 775. [CrossRef]

126. Cheng, Z.; Wang, L.; Sun, W.; Zhang, Y.; Zhou, C.; Su, Y.; Li, W.; Sun, T.; Zhao, X.; Li, X.; et al. Pattern of auxin and cytokinin responses for shoot meristem induction results from the regulation of cytokinin biosynthesis by AUXIN RESPONSE FACTOR 3. Plant Physiol. 2013, 161, 240-251. [CrossRef]

127. Zhao, Z.; Andersen, S.U.; Ljung, K.; Dolezal, K.; Miotk, A.; Schultheiss, S.J.; Lohmann, J.U. Hormonal control of the shoot stem-cell niche. Nature 2010, 465, 1089-1092. [CrossRef]

128. Liu, Z.; Li, J.; Wang, L.; Li, Q.; Lu, Q.; Yu, Y.; Li, S.; Bai, M.; Hu, Y.; Xiang, F. Repression of callus initiation by the miRNA-directed interaction of auxin-cytokinin in Arabidopsis thaliana. Plant J. 2016, 87, 391-402. [CrossRef]

129. Yu, S.; Galvao, V.C.; Zhang, Y.-C.; Horrer, D.; Zhang, T.-Q.; Hao, Y.-H.; Feng, Y.-Q.; Wang, S.; Schmid, M.; Wang, J.-W. Gibberellin regulates the Arabidopsis floral transition through miR156-targeted SQUAMOSA PROMOTER BINDING-LIKE transcription factors. Plant Cell 2012, 24, 3320-3332. [CrossRef]

130. Wu, G.; Park, M.Y.; Conway, S.R.; Wang, J.-W.; Weigel, D.; Poethig, R.S. The sequential action of miR156 and miR172 regulates developmental timing in Arabidopsis. Cell 2009, 138, 750-759. [CrossRef]

131. Achard, P.; Herr, A.; Baulcombe, D.C.; Harberd, N.P. Modulation of floral development by a gibberellin-regulated microRNA. Development 2004, 131, 3357-3365. [CrossRef]

132. Zuo, J.; Zhu, B.; Fu, D.; Zhu, Y.; Ma, Y.; Chi, L.; Ju, Z.; Wang, Y.; Zhai, B.; Luo, Y. Sculpting the maturation, softening and ethylene pathway: The influences of microRNAs on tomato fruits. BMC Genom. 2012, 13, 1-12. [CrossRef]

133. Schommer, C.; Palatnik, J.F.; Aggarwal, P.; Chetelat, A.; Cubas, P.; Farmer, E.E.; Nath, U.; Weigel, D. Control of jasmonate biosynthesis and senescence by miR319 targets. PLoS Biol. 2008, 6, e230. [CrossRef]

134. Adams, E.; Turner, J. COI1, a jasmonate receptor, is involved in ethylene-induced inhibition of Arabidopsis root growth in the light. J. Exp. Bot. 2010, 61, 4373-4386. [CrossRef]

135. Di, D.-W.; Sun, L.; Wang, M.; Wu, J.; Kronzucker, H.J.; Fang, S.; Chu, J.; Shi, W.; Li, G. WRKY46 promotes ammonium tolerance in Arabidopsis by repressing NUDX9 and indole-3-acetic acid-conjugating genes and by inhibiting ammonium efflux in the root elongation zone. New Phytol. 2021, 232, 190-207. [CrossRef]

136. Di, D.-W.; Wu, L.; Luo, P.; Zhang, L.; Zhang, T.-Z.; Sun, X.; Wei, S.-D.; An, C.-W.; Guo, G.-Q. Analysis the role of Arabidopsis CKRC6/ASA1 in auxin and cytokinin biosynthesis. J. Plant Biol. 2016, 59, 162-171. [CrossRef] 
137. Di, D.-W.; Wu, L.; Zhang, L.; An, C.-W.; Zhang, T.-Z.; Luo, P.; Gao, H.-H.; Kriechbaumer, V.; Guo, G.-Q. Functional roles of Arabidopsis CKRC2/YUCCA8 gene and the involvement of PIF4 in the regulation of auxin biosynthesis by cytokinin. Sci. Rep. 2016, 6, 36866. [CrossRef]

138. Datta, R.; Paul, S. Plant microRNAs: Master regulator of gene expression mechanism. Cell Biol.Int. 2015, 39, 1185-1190. [CrossRef]

139. Chitwood, D.H.; Nogueira, F.T.S.; Howell, M.D.; Montgomery, T.A.; Carrington, J.C.; Timmermans, M.C.P. Pattern formation via small RNA mobility. Gene. Dev. 2009, 23, 549-554. [CrossRef]

140. Zheng, L.-L.; Qu, L.-H. Application of microRNA gene resources in the improvement of agronomic traits in rice. Plant Biotechnol. J. 2015, 13, 329-336. [CrossRef]

141. Chang, H.; Yi, B.; Ma, R.; Zhang, X.; Zhao, H.; Xi, Y. CRISPR/cas9, a novel genomic tool to knock down microRNA in vitro and in vivo. Sci. Rep. 2016, 6, 22312. [CrossRef]

142. Chen, L.; Cheng, X.; Cai, J.; Zhan, L.; Wu, X.; Liu, Q.; Wu, X. Multiple virus resistance using artificial trans-acting siRNAs. J. Virol. Methods 2016, 228, 16-20. [CrossRef]

143. Djami-Tchatchou, A.T.; Sanan-Mishra, N.; Ntushelo, K.; Dubery, I.A. Functional roles of microRNAs in agronomically important plants-potential as targets for crop improvement and protection. Front. Plant Sci. 2017, 8, 378. [CrossRef]

144. Liu, Q.; Chen, Y.-Q. A new mechanism in plant engineering: The potential roles of microRNAs in molecular breeding for crop improvement. Biotechnol. Adv. 2010, 28, 301-307. [CrossRef]

145. Tiwari, M.; Sharma, D.; Trivedi, P.K. Artificial microRNA mediated gene silencing in plants: Progress and perspectives. Plant Mol. Biol. 2014, 86, 1-18. [CrossRef]

146. Zhao, Y.; Dai, Z.; Liang, Y.; Yin, M.; Ma, K.; He, M.; Ouyang, H.; Teng, C. Sequence-specific inhibition of microRNA via CRISPR/CRISPRi system. Sci. Rep. 2014, 4, 3943. [CrossRef] 